\title{
COIN PERCEPTION STUDIES AND THE CONCEPT OF SCHEMATA
}

\author{
HAROLD G. MCCURDY \\ University of North Carolina
}

The proposition that perception is influenced by object value and perceiver need has enjoyed an exciting career since it was given prominence by Bruner and Goodman in an oral and, later, a printed report (3) of dramatic differences between rich and poor children in their judgments of coin sizes. Whether that study or subsequent ones can be said to have upheld the proposition may be questionable; but the effect on psychologists is beyond doubt. They were refreshed and stimulated. The ideas, the experimental approach, and the results were new, and quite obviously appealed to current needs.

It was with a little surprise that, perhaps two years ago, while ruffling through the time-blurred pages of the Psychological Review of 1906, I ran across an article which seemed to bear some kinship to contemporary studies but which had not, as far as I was aware, been referred to in the recent literature. That accident started a train of thought which, with the aid of a few other bits of historical material, has led to the present paper. Very briefly, what I have to say is this. First, there are certain points of agreement between several coin studies, old and new, but the agreement is not such as to encourage the Bruner-Goodman theory that perception itself is distorted by value and need, at least directly. Second, there may be some advantage in applying the concept of schemata to the coin perception problem, and to other perceptual problems as well. The concept, which goes back to Head and Bartlett, has been very recently discussed in this Journal by Vernon (18).

\section{Old Light on a New Argument}

The 1906 paper alluded to above was by Robert MacDougall (11). It tended to show that the symbolic difference between two different denominations of paper money ( $\$ 1$ and $\$ 10)$ is reflected in judgments of their weight. "How many bills together equal the weight of a silver dollar?" was the question MacDougall put to his schoolgirl subjects. To avoid suggestion effects on the main comparison he wished to make, he specified only the one denomination or the other when addressing his query to any particular group. In either case, the correct answer is about 20. The guesses obtained ranged from 5 to a wild 10,000 or so. Not overly concerned about the range, MacDougall thought that the averages and medians favored the view that monetary value has a positive effect on estimates of physical quantity. Some of his data are presented in Table 1.

\section{TABLE 1}

Estimates of Number of Bills Needed to EQUal. Weight of Silver Dollar, MacDougall (10)

\begin{tabular}{c|r|r|r|r|r|c}
\hline \hline \multirow{2}{*}{ School } & \multicolumn{3}{|c|}{$\$ 1$} & \multicolumn{3}{|c}{$\$ 10$} \\
\cline { 2 - 7 } & \multicolumn{1}{|c|}{$N$} & Avg & Mdn & $N$ & Avg & Mdn \\
\hline IV & 67 & 215 & 20 & 56 & 125 & 20 \\
V & 155 & 98 & 25 & 116 & 97 & 25 \\
VI & 78 & 99 & 25 & 66 & 44 & 20 \\
VII & 40 & 84 & 50 & 42 & 52 & 25 \\
\hline
\end{tabular}


MacDougall's inquiry does not stand alone at that period. It was designed, in fact, to follow up a note by J. F. Messenger in Science in 1902 (12) which had elicited at least two other brief communications in the same journal, one by Pierce in 1902 (16) and one by Slosson in 1903 (17). All three of these writers offer statistical proof that the weight of paper money is underestimated when compared in memory with coins of gold or silver-a result which may or may not agree with value theories of perception, depending upon how value is defined. But there should certainly be a hearty welcome from that quarter for Messenger's finding that university students and faculty members considered $\$ 1$ bills lighter than those of higher denomination.

Half a century ago, then, the minds of American psychologists were busy with a question which, in slightly altered form, has concerned us during the last decade. The technique of these early studies may be criticized, and it may be doubted whether the numerical guesses produced by the subjects de- serve to be taken literally; but there is a relevance to present-day research on perception of valued objects which should not be ignored simply because the question then was cast in terms of memory judgments unaided by sensory inspection. The problem was the same.

In 1913 G. C. Myers published a monograph on incidental memory (13) which is directly pertinent to recent developments. Among other things he investigated the accuracy with which people estimate the sizes of familiar coins. $\mathrm{He}$ presented his numerous subjects with a sheet of cardboard bearing compass-drawn circles ranging in diameter from 9 to 44 millimeters by 1 -millimeter steps, and asked them to select from these the six circles corresponding most nearly in size to penny, nickel, dime, quarter, half-dollar, and dollar. ${ }^{1}$ In

${ }^{1} \mathrm{He}$ considered the circles with diameters of $19,21,18,24,31$, and $38 \mathrm{~mm}$. as fairly representing the sizes of the penny, nickel, dime, quarter, balf-dollar, and dollar, respectively, the precise diameters of which he gives on the authority of the U. S. Treasury as $19.05,21.2,17.9,24.25,30.6$, and $38.1 \mathrm{~mm}$.

TABLE 2

Estimates of Diameters of Coins (in Minlimeters) BASED ON MEMORY and VisUal InSPECTION

\begin{tabular}{|c|c|c|c|c|c|}
\hline Standards & $\underset{(17.8)}{\text { Dime }}$ & $\begin{array}{l}\text { Cent } \\
(19.0)\end{array}$ & $\begin{array}{l}\text { Nickel } \\
(21,2)\end{array}$ & $\underset{(24.1)}{\text { Quarter }}$ & $\begin{array}{l}\text { Half Dollar } \\
(30.5)\end{array}$ \\
\hline \multicolumn{6}{|c|}{ Memory } \\
\hline $\begin{array}{l}\text { Myers }(N=58-59) \\
\text { Bruner and Goodman } \quad \text { Size }=\text { Area? } \\
\quad(N=20) \\
\text { Carter and Schooler }(N=48)\end{array}$ & $\begin{array}{l}15 \\
18.8 \\
19.9 \\
16.6\end{array}$ & $\begin{array}{l}17 \\
19.4 \\
20.4 \\
18.7\end{array}$ & $\begin{array}{l}19.7 \\
23.2 \\
25.4 \\
21.1\end{array}$ & $\begin{array}{l}25.1 \\
27.8 \\
31.9 \\
26.7\end{array}$ & $\begin{array}{l}34 \\
35.6 \\
41.4 \\
34.6\end{array}$ \\
\hline \multicolumn{6}{|c|}{ Inspection } \\
\hline $\begin{array}{l}\text { Bruner and Goodman } \quad \begin{array}{l}\text { Size }=\text { Area? } \\
\text { Size }=\text { Diam.? }\end{array} \\
\quad(N=20) \\
\text { Bruner and Rodrigues }(N=30) \\
\text { Carter and Schooler }(N=48) \\
\text { Carter and Schooler Cardboard Discs* } \\
\quad(N=48)\end{array}$ & $\begin{array}{l}20.2 \\
23.0 \\
16.4 \\
16.6\end{array}$ & $\begin{array}{l}20.4 \\
22.1 \\
19.3 \\
18.1 \\
18\end{array}$ & $\begin{array}{l}23.6 \\
26.3 \\
22.7 \\
21.1 \\
21.1\end{array}$ & $\begin{array}{l}28.2 \\
33.0 \\
28 \\
25.6 \\
24.4\end{array}$ & $\begin{array}{l}34.6 \\
39.5 \\
33.5 \\
31.9\end{array}$ \\
\hline
\end{tabular}

* The diameters of the discs were $17.5,18.7,21.2,24,1,30,6$, thus differing slightly from the diameters of the coins. 
Table 2, alongside some modern data, I have entered his results for fifth-grade boys and girls, converting his error figures by a simple calculation into average estimated diameters. The agreement of Myers with Carter and Schooler (7) is very close. Though the correspondence with Bruner and Goodman is less close, it is still pretty good, provided that we assume that their "size" equals area rather than diameter-a problem of interpretation to be discussed below.

The features of the data in the first half of Table 2 most deserving our attention are brought out in Fig. 1. The memory estimates from all three studies follow the same slope, deviating from the slope of perfect match (indicated by the heavy line) in such a way that the size range between largest and smallest coins is greater than it would be if the estimates were perfectly accurate. According to Myers and according to Carter and Schooler, the smaller coins are underestimated and the larger overestimated. According to Bruner and Goodman, all sizes are overestimated, but slope and range are not thereby thrown out of agreement with the other two sources of data. In sum, three independent studies of children at about the fifth-grade level agree that in making size estimates of familiar coins from memory the children produce a correct order of coins according to size, and slightly exaggerate the differences between them.

How should these facts be interpreted? Bruner and Rodrigues (5), fighting a kind of rear-guard action against Carter and Schooler in defense of some earlier conclusions, have argued that the relatively greater exaggeration of size in the estimates of coins of larger denomination is further evidence for the hypothesis that symbolic value influences the estimate of physical magnitude. The argument is weak, and it seems to dis- regard the fact that smaller coins may be underestimated; the dime, for instance, is underestimated, and underestimated to a greater degree than either penny or nickel, according to Myers, and Carter and Schooler, as Fig. 1 and Table 2 show. Should we not say that memory, in stretching out the range of coin sizes, commits a "good" error? If we attend merely to individual coins, we note overestimation here and underestimation there; but if we attend to the whole series, we see that the order of sizes is maintained, perhaps guaranteed by the exaggeration of differences. After all, is it not, practically, more important to realize that the dime is smaller than the penny than to know either the absolute sizes or the exact amount of difference between them? One would scarcely deny that symbolic value enters into the construction of such a functional schema. But how? The exaggeration of differences would be more useful than sheer magnification of individual items, and this is what appears to happen.

Perhaps it might be laid down as a general principle that, wherever it is important to have clarity, there will be a tendency to exaggerate differences within any closely graded series, and thus, in a case like the present, lead to a slope steeper than the slope of perfect match. In the case of series of few members and large differences between adjoining members, there might be some lowering of the slope, since this could be afforded without the risk of confusion. But the coin series is a fairly closely graded one, and to keep them separate in memory seems to require some exaggeration of difference.

Before going any farther in the discussion, let me explain a doubtful aspect of Table 2, indicated by the question marks. In trying to put all available information into identical form as millimeters of diameter, $\mathrm{I}$ had to treat 


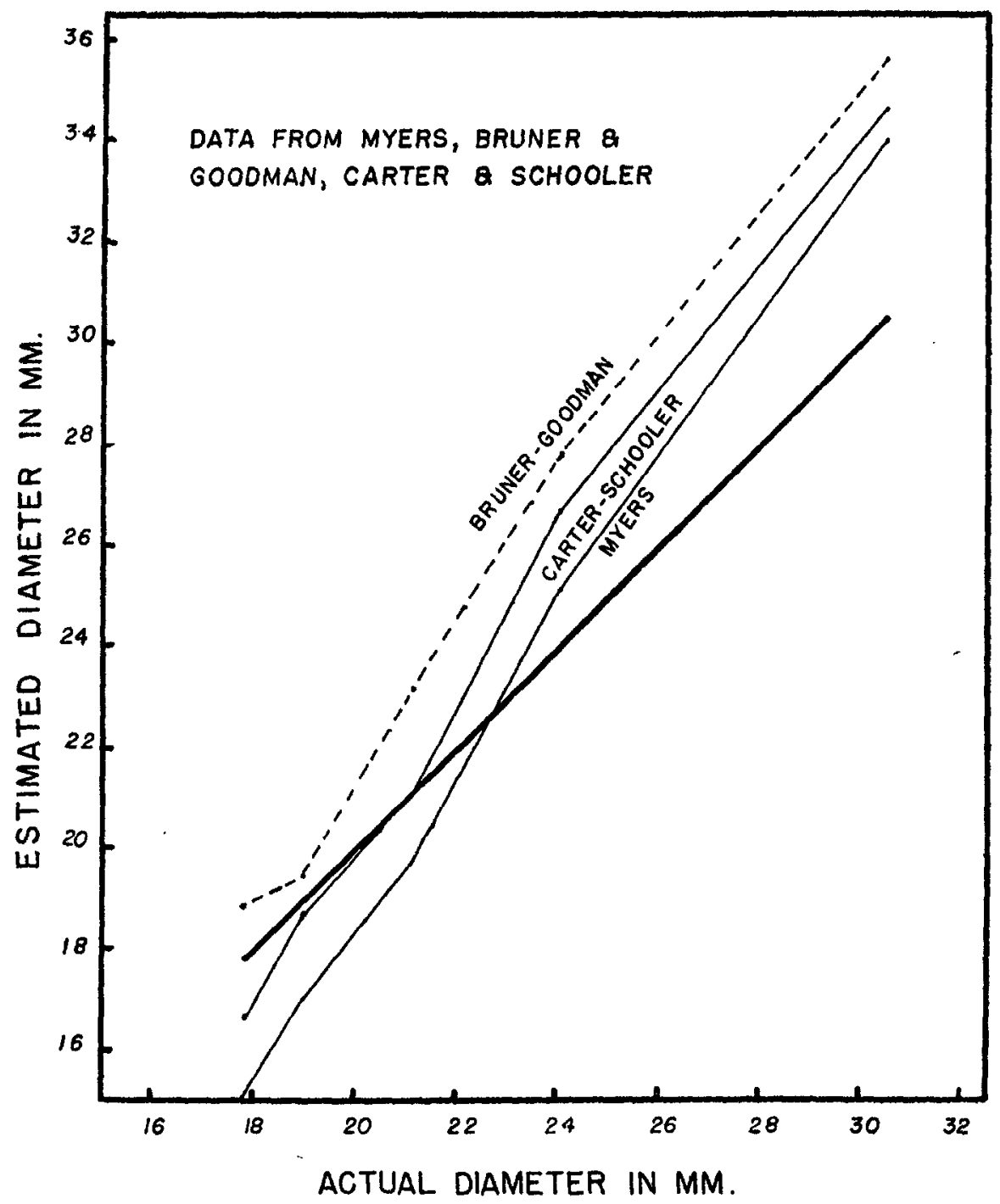

Fic. 1. Accuracy of memory for size of coins as shown by three independent studies.

the percentages of deviation published by Bruner and Goodman according to two different assumptions. Since they are never specific about it, they could mean either area or diameter when they refer to "size." Carter and Schooler apparently take them to mean diameter. The subsequent Bruner and Rodrigues article does not deny that assumption. Nevertheless, it is my guess that "size" in the Bruner and Goodman article means area. My reason is that the diameters derived according to this assumption from their percentage figures harmonize better with the other data in Table 2, including those from Bruner and Rodrigues, than do diameters derived according to the other assumption. Incidentally, the meaning of the percentage figures in the Bruner and 
Goodman study is troubled by the same ambiguity. If two investigators obtained precisely the same results but reported percentage deviations on the two different bases, one the one way and one the other, the one reporting on the basis of diameter would appear to have deviations roughly half as large as the one reporting on the basis of area.

\section{The Schema Concept}

In the preceding discussion of size estimates I once used the term schema, in what I believe is the sense recommended by Vernon in her recent topical and suggestive paper on perception. No doubt there are other terms that would do as well, all meaning some kind of cognitive disposition not in itself directly experienced but manifesting itself in imagining, remembering, perceiving, and acting. This is not the place to ferret out the ancestors of the term and all the contemporary kith and kin. Suffice it to say that Bartlett in his book on remembering (1) took it over from Head, with whom he had discussed it for years, gave it greater generality and a more psychological orientation, and passed it on to others who found it useful, especially in Great Britain. The reader interested in more detail should turn to Bartlett (1), Oldfield (14), Oldfield and Zangwill (15), and follow up some of their references. The schema is organically built up out of past experiences and reactions, it functions as an orienting and stabilizing factor in new contacts with the environment, and, although it is constantly subject to change both because of organismic dynamics and environmental variations, it may come to govern behavior quite rigidly in exceptional cases. As Vernon says, "The essential point to note is that the use of a concept such as that of the schema reflects the fact that our percepts, thoughts, and behavior are on the whole consistent and orderly-reasonably appropriate though not necessarily logical-and that they are consistently related to previous acts of perceiving, thinking, and behaving" (18, p. 181).

Now, schemata appear to be inadequately appreciated. Brunswik, for example, betrays surprise at the results of an experiment by Bolles and Bailey showing how extremely little the direct vision of familiar objects improves estimates of size based upon mere verbal identification alone (6).

A perfectly accurate schema, of course, could not be improved upon by any amount of sensory inspection, and perhaps there are many schemata so nearly accurate that improvement would be difficult. But everyday observation suggests that a schema may be resistant to improvement even when there is plenty of room for it. One reason is that the presence of a schema obviates the necessity of a close examination of objects, so long as it works within the wide limits of tolerance usually permitted by the environment; the name of an object is about as informative as sensory commerce with it, if the sensory commerce functions chiefly as a reminder to the observer of the appropriate cognitive reference file, as it often does.

Such reflections lead to the hypothesis that accuracy of size estimation will be less for perceived objects belonging to a definite schema, unless the schema has been very carefully developed, than for perceived objects lacking such a schema. Figure 2 supports this hypothesis with data drawn from Carter and Schooler. Inspection of the coins does improve the estimates based upon the schema operating in memory, but the estimates for the cardboard discs, which presumably are less schematized than the coins, are more accurate still. The evidence is admittedly slender, but, such as it is, it is not contradicted by 


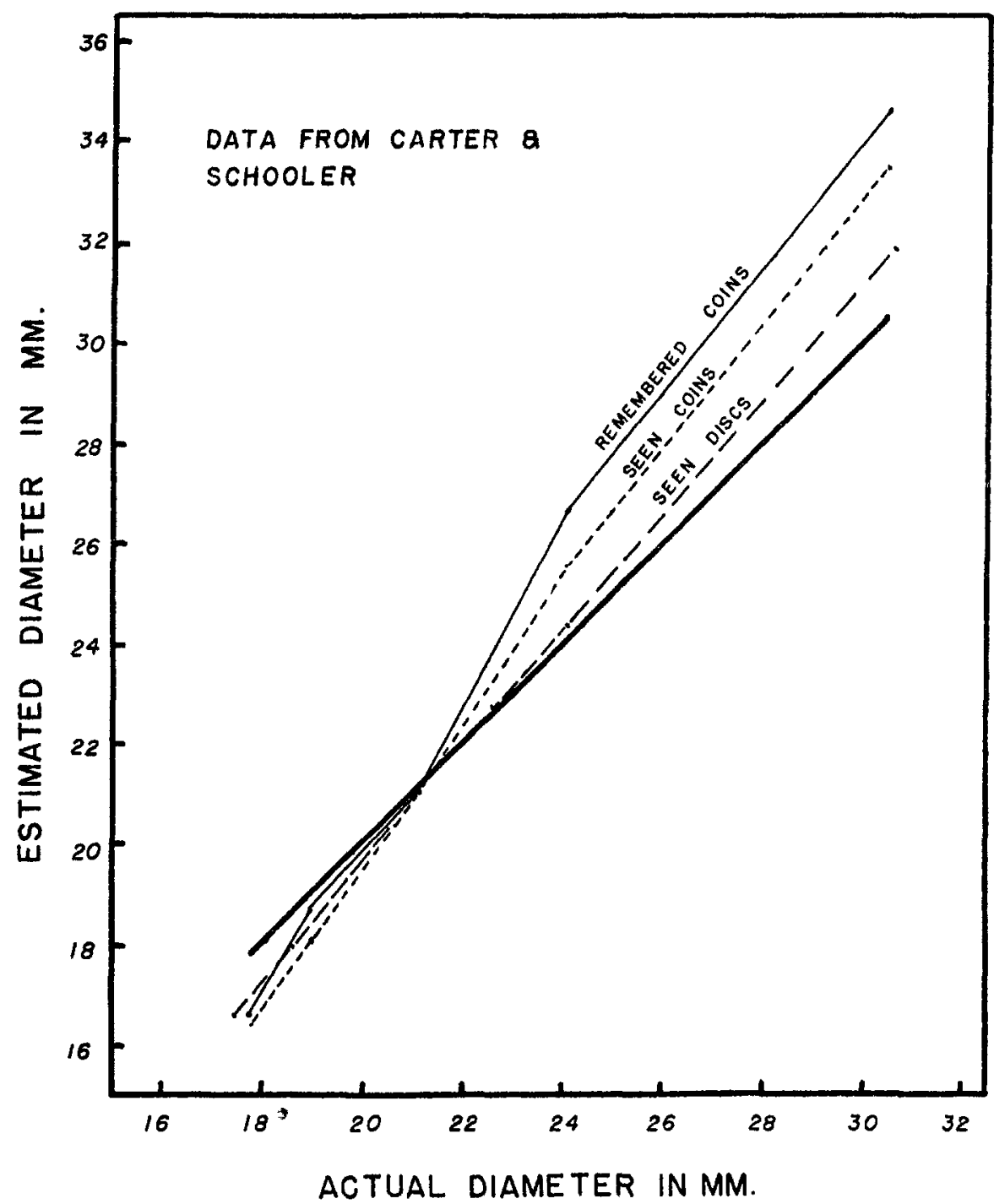

FIG. 2. Comparative accuracy of memory and immediate perception.

the data from Bruner and Goodman; if anything it is only too well supported. One expects sensory inspection to result in some improvement where the memory estimate is inaccurate; but, contrary to this expectation, just the opposite happened in the Bruner and Goodman study, as nearly everybody knows. On the other hand, the estimation of cardboard discs, both in this study and in the later one by Bruner and Rodrigues, was very accurate indeed.

\section{Emotronal EFFects?}

I have argued that under ordinary circumstances one would expect estimates of size to be progressively better as one passes from an estimate based upon a memory schema, through one representing the interaction of schema 
and direct sensory inspection, to one based primarily upon direct sensory inspection and relatively little upon a schema, as illustrated in Fig. 2. But the hypothesis is not prepared to cope with emotional perturbations, however caused.

It is not exactly clear what the conditions of the Bruner and Goodman experiment were from the point of view of the psychology of the subjects. The children were selected as representing two distinct economic classes, and it was assumed that the class membership implied a predictable state of need with regard to money, the poor being supposedly greedier for it than the rich, and tending, therefore, to overestimate coin sizes, especially when the coins had taken on burning reality by being placed within their very grasp. But this theoretical position is modified in the Bruner and Rodrigues paper; it is confessed that class membership is an unreliable index of need state, and the reader is urged to put more trust in the type of approach "where a money-value system is built up and extinguished experimentally," as in the study by Lambert, Solomon, and Watson (10). There was, apparently, no deliberate manipulation of the value system by Bruner and Goodman in their treatment of their subjects or in the experimental arrangements. The merest hint of such a variable is found in their manner of presenting the coins. These were presented, verbally and materially, in ascending and descending order of value rather than randomly or in order of size. Whether this procedure accounts for the slight tendency to dislocate the dime from its proper relative position in the size series is an open question. As to producing a general overestimation of size for all the coins, however, it would scarcely suffice. Were the children emotionally aroused in any way by the experimenters when the coins were pre- sented, as might conceivably have happened if there had been, for instance, a promise of monetary reward? Apparently not. The conditions of the experiment were, presumably, of a neutral, strictly psychophysical kind, implying no reward and arousing no excitement except such as might have been derived spontaneously from the need states appropriate to the rich and the poor. The startling results, now that the classmembership hypothesis has been abandoned, are left hanging without specific explanation.

The possibility of emotion in the Lambert, Solomon, and Watson study is much clearer. Very young children ( 3 to 5 years) were used as subjects. Those in the experimental group repeatedly obtained a poker chip by turning a crank a certain number of times and then got candy by inserting the poker chip into a slot; the control subjects likewise turned a crank and received candy, but without the intermediation of the poker chip. After ten days the experimental group, having been often reinforced (10 or 50 times), displayed a significantly higher size estimation of the poker chip than in pretest trials or after extinction; interestingly enough, there was also a slight rise in the control group. A repetition of the experiment, with certain modifications, produced similar results, as reported by Lambert and Lambert (9). Now, nothing is said in the Lambert studies about the emotions of these little children. Nevertheless, it may be fair to guess that the process of reinforcement generated some degree of pleasant excitement, whereas the extinction experience may have been somewhat sobering. The former emotional condition might have been more conducive to an expansive sort of inaccuracy, especially in the presence of the stimulating poker chip, than the latter. At any rate, it is not unreasonable to look for an explanation 
of the expanded estimates in the general pleasant emotion induced in both sets of children by the interesting and rewarding game, and especially induced in the experimental group by the fact that the poker chip which they had to judge was an intrinsic part of the game, suggesting by its presence still more candy or other exciting outcome. Perhaps this is what is meant by Lambert and Lambert when commenting on a variation of the experiment in these words: "Still another way of discussing these data is that there is an effect at least analogous to stimulus intensity involved. That is, the white token is a stronger stimulus, at least in its visceral prededications, and it results in an amplification of the judgment response" (9, p. 509). One should not expect children of 3 to 5 years of age to be very critical in making the sensorimotor adjustments required in these experiments for indicating their judgments, when they are under the stress of pleasant excitement. That the error happens to come out in the direction of a larger estimate rather than a smaller may be an expression of an affective law, though at the moment I can think of no better evidence for such a law than the familiar rough observations concerning expansion of the body and bodily gestures in sthenic states, fluctuations of handwriting size with changes of mood, the general overplus of activity in excited children, and so on.

\section{Summary and Concluding Remarks}

The following principal conclusions emerge from the present discussion: (a) The memory schema for coin sizes, while stretching out the total range and slightly exaggerating the differences between coins, preserves the correct order; (b) there is no evidence that this order is significantly disturbed by values and needs; (c) a memory schema, such as that for coin size, tends to resist correc- tion by sensory contact with objects, contact serving as little more than a fleeting reminder, like a name; $(d)$ departures from accurate size estimation which have been taken to favor the hypothesis that increase of value induces phenomenal magnification might better be interpreted as the result of the interference of expansive emotional states with meticulous adjustments.

The above conclusions refer to certain specific studies and to results stated in the form of averages. There is no intent to deny that values and needs may influence perception in some way, though presumably more through schemata than directly. The experimental evidence is weak, however, and very fragmentary.

One final point may be made. If a strong case is ever to be developed for need and value effects on perception, it may be supposed that it will have to be founded on the careful analysis of individual data. Perceivers are always individuals, and schemata, too, are individual matters, even though there may be percepts and schemata which are widely shared in a society or species. Perhaps it is not scientifically desirable to restrict ourselves so narrowly to average data, to neat tabulations of measurements and tests of significance, while neglecting to describe fully the general behavior of our subjects, and neglecting, in fact, to study the pattern of data for each individual. Klein, Schlesinger, and Meister (8) have done us a service, I believe, in pointing out the overwhelming importance of the individual differences in their own value-perception study, and have properly emphasized that mass statistics may completely hide the value determinants which may be operating quite powerfully in individuals taken singly.

\section{REFERENCES}

1. Bartlett, F. C. Remembering. Cambridge: Univer. Press, 1932. 
2. BRUNer, J. S. One kind of perception: a reply to Professor Luchins. Psychol. Rev., 1951, 58, 306-312.

3. Bruner, J. S., \& Goodman, C. C. Value and need as organizing factors in perception. J. abnorm. soc. Psychol., 1947, 42, 33-44.

4. Bruner, J. S., \& Postman, L. Perception, cognition, and behavior. J. Pers., 1949, $18,14-31$.

5. Bruner, J. S., \& Ropriguts, J. S. Some determinants of apparent size. $J$. $a b$ norm. soc. Psychol., 1953, 48, 17-24.

6. BRUNSWIK, E. In defense of probabilistic functionalism: a reply. Psychol. Rev., $1955,62,236-242$.

7. Carter, L. F., \& Schooler, K. Value, need, and other factors in perception. Psychol. Rev., 1949, 56, 200-207.

8. Klein, G. S., Schlisinger, H. J., \& Metster, D. E. The effect of personal values on perception: an experimental critique. Psychol. Rev., 1951, 58, 96112.

9. Lambert, W. W., \& Lambert, E. C. Some indirect effects of reward on children's size estimation. J. abnorm. soc. Psychol., 1953, 48, 507-510.

10. Lambert, W. W., Solomon, R. L., \& Watson, P. D. Reinforcement and extinction as factors in size estimation. J. exp. Psychol., 1949, 39, 637-641.
11. MacDougaLL, $R$. On secondary bias in objective judgment. Psychol. Rev., 1906, $13,97-120$.

12. Messenger, J. F. How many one-dollar bills will equal in weight a five-dollar gold piece? Science, 1902, 15, 672-673.

13. MYers, G. C. A study in incidental memory. Arch. Psychol., 1913, 4, No. 26, 1-108.

14. Oldfield, R. C. Memory mechanisms and the theory of schemata. Brit. J. Psychol, 1954, 45, 14-23.

15. OldFIELd, R. C., \& ZangwirL, O. L. Head's concept of the schema and its application in contemporary British psychology. Part I. Head's concept of the schema. Part II. Critical analysis of Head's theory. Part III. Bartlett's theory of memory. Part IV. Wolters' theory of thinking. Brit. $J$.

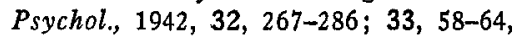
113-129; 1943, 33, 143-149.

16. Pifrce, A. H. Guesses on the relative weights of bills and coins. Science, $1902,16,745$.

17. Stosson, E. E. Guesses on the relative weights of bills and coins. Science, 1903, 17, 189.

18. Vernon, M. D. The functions of schemata in perceiving. Psychol. Rev., 1955, 62, 180-192.

(Received June 6, 1955) 